\title{
A Mulher Empreendedora e o delineamento do perfil Profissional da Personal Trainer
}

Bruna Cibele Pacheco Gut ${ }^{1}$, Marligia Souza Santos ${ }^{2}$, Erika Maria Jamir de Oliveira ${ }^{3}$

\begin{abstract}
Resumo: Este estudo teve como objetivo identificar o perfil da empreendedora que atua como personal trainer e, descrever as características do comportamento empreendedor destas profissionais que atuam no Município de Petrolina-PE. A pesquisa possui caráter descritivo, e a técnica utilizada foi o levantamento, os dados foram coletados mediante entrevistas instrumentalizada por formulários com todas as profissionais identificadas nas academias em situações regulares no pleno exercício legal da atividade. Os resultados indicam que as profissionais possuem as CCE, pois, a maioria das características a mediana foi 4, porém, as características correr ricos moderados e estabelecimento de metas foram mais baixas. Estas características podem ser desenvolvidas e aperfeiçoadas com vistas a melhoria dos resultados.
\end{abstract}

Palavras-chave: Empreendedorismo Feminino. Educação física. Personal Trainer. Características do comportamento empreendedor.

\section{The Entrepreneurial Woman and the design of Professional profile of Personal Trainer}

\begin{abstract}
This study aimed to identify the profile of the female enterperneur who acts as a personal trainer and describe the characteristics of the entrepreneurial behavior of professionals working in the city of Petrolina-PE. This research has a descriptive character, and the technique that was used was the survey, the data was collected through instrumentalized interviews with forms with all the professionals identified in the academies in normal situations. The results indicate that as professionals they have "CCE", therefore, most of the characteristics of the median was 4 , however, the characteristics take moderate risks and the establishment of goals were lower. These features can be developed and improved with concern to better results.
\end{abstract}

Key-words: Female Entrepreneurship; Physical Education; Personal Trainer; Characteristics of the Entrepreneur's Behaviour.

\section{Introdução}

Atualmente as mulheres têm se destacado mais no mercado de trabalho. Este fato suscita um crescente interesse por parte do setor público e da comunidade científica, no fenômeno do empreendedorismo, ao qual a mulher participa efetivamente (NOGUERA; ALVAREZ; URBANO, 2013 apud ALPERSTEDT; FERREIRA; SERAFIM, 2014).

\footnotetext{
${ }^{1}$ Faculdade de Ciências Aplicadas e Sociais de Petrolina (FACAPE) brunagut @icloud.com;

${ }^{2}$ Faculdade de Ciências Aplicadas e Sociais de Petrolina (FACAPE) marligiassantos@gmail.com;

${ }^{3}$ Universidade Federal do Vale do São Francisco (UNIVASF) erikamariajamirdeoliveira@ gmail.com
} 
De acordo com Metz (2015) as mulheres, hoje, compõem uma parte significativa do mercado de trabalho, além disso, esse crescimento permanece ascendente e a permanência das mulheres também tem sido observada, devido a melhores condições e oportunidades.

Porém, mesmo com tantos avanços no empreendedorismo feminino, a mulher ainda encontra alguns desafios para empreender. Entre os principais desafios observados, pode-se destacar a dificuldade em conseguir investimentos para o negócio por parte das instituições financeiras, o desestímulo devido a alguns dados desencorajadores do mercado, a educação desigual e o sexismo, que vem a ser a descriminação com base em estereótipos de gênero (SEBRAE, 2016). Segundo Kanan (2010), mesmo com um alto número de mulheres em empresas, são poucos os cargos de liderança ocupados por elas, devido a atitudes discriminatórias e/ou sexistas, revelando que ainda existe preconceito.

Uma pesquisa desenvolvida pela GEM - Global Entrepreneurship Monitor, em 2010, mostra que $35 \%$ de lares no Brasil são sustentados por mulheres e que no mercado de trabalho $42 \%$ das vagas são ocupadas por elas. Na política, a participação ainda é pequena, mas no mundo dos negócios a mulher brasileira está entre as que mais empreendem. Para o professor e pesquisador de empreendedorismo Louis Filion, esse avanço está relacionado a determinadas características empreendedoras que a mulher possui, como o interesse de pesquisa mercadológica, estabilidade, melhor preparação, planejamento, gerenciamento, participativo, preocupação com empregados e clientes (GEM, 2010).

O empreendedorismo é um campo de estudo conhecido como a arte de desenvolver a criatividade e de inovar assumindo riscos. É um tema bastante discutido nos últimos tempos e, em um mundo cada vez mais competitivo é necessário que se tenha líderes empreendedores para um melhor desenvolvimento econômico (BAGGIO; BAGGIO, 2015).

Outro tema em destaque nos últimos anos, é a pratica de treinamento personalizado. Muitas pessoas têm buscado este tipo de treinamento para alcançarem seus objetivos em relação ao corpo. Elas realizam os mais diversos exercícios físicos acompanhados de um personal trainer ou treinador personalizado (OLIVEIRA, 1999 apud SALCEDO, 2010). De acordo com Sanches (2006), o personal trainer é um “profissional formado/graduado em Educação Física que ministra aulas personalizadas, formulando e executando programas de treinamento específicos para cada aluno". Estes profissionais também são considerados empreendedores e são os indivíduos analisados neste estudo. 
Assim, o presente trabalho tem por objetivo delinear o perfil empreendedor, das mulheres que atuam como personal trainer, na cidade de Petrolina-PE, com o intuito de responder ao seguinte questionamento: em quais níveis, as características do comportamento empreendedor, estão presentes no perfil destas profissionais?

Diante do exposto, considerou-se relevante identificar o perfil das personal trainers que atuam nas academias da cidade de Petrolina-PE para analisar as suas características das necessidades motivacionais que orientam o seu comportamento empreendedor. Produzir o presente estudo também se justifica, pelo fato de que, o tema empreendedorismo, nos seus diversos segmentos, ainda carece de dados de pesquisa e de estudos que possam auxiliar no seu entendimento e desenvolvimento. Outra contribuição que atribuímos a esse estudo é possibilitar a compreensão da história do empreendedorismo e seus conceitos, das características do comportamento empreendedor, do empreendedorismo feminino e sobre a profissão personal trainer.

\section{Quem é o empreendedor?}

De acordo com Baggio e Baggio (2015) o ato de empreender é a arte de fazer acontecer, com criatividade e motivação. É o prazer de realizar projetos pessoais e organizacionais, de modo sinérgico e inovador, desafiando permanentemente as oportunidades e os riscos, além de ser proativo diante de questões não resolvidas. Empreender é o despertar do indivíduo para aproveitar de forma integral suas potencialidades racionais e intuitivas, e, buscar autoconhecimento em um aprendizado permanente, estando aberto para novas experiências e novos paradigmas.

Um primeiro exemplo de uma iniciativa empreendedora é creditado a figura de Marco Polo, devido à sua tentativa de estabelecer uma rota comercial para o Oriente. Marco Polo, no papel de empreendedor, assinou um contrato com um investidor (um indivíduo que possuía dinheiro, atualmente conhecido como capitalista) para vender as mercadorias do mesmo (DORNELAS, 2016).

Assim como Marco Polo, um empreendedor, segundo Dornelas (2016), é o indivíduo que é capaz de detectar uma oportunidade e criar um negócio para capitalizar através dele, 
assumindo riscos calculados. De acordo com ele, através da análise de estudos já existentes, pelo menos os seguintes aspectos irão constar em relação ao empreendedor no Quadro 1.

Quadro 1: Aspectos comuns ao empreendedor

- A iniciativa para criar um novo negócio;

- Além de ser apaixonado pelo que faz;

- Utilizar os recursos disponíveis de forma criativa;

○ Transformando o ambiente social e econômico onde atua;

- Assumir riscos;

○ Levando em consideração a possibilidade de fracasso.

Fonte: Adaptado de Dornelas (2016).

Independente da falta de um consenso a respeito da definição de empreendedor, a maioria dos pesquisadores concorda que os indivíduos que empreendem têm características especiais que os diferem dos demais (GARTNER, 1988 apud CASTRO, 2011).

\section{Características do comportamento empreendedor}

A teoria de base comportamental tem como foco central identificar, em indivíduos que criaram empreendimentos, características de seu comportamento. Os estudiosos da área, verificaram que existem características psicológicas, que diferenciam os empreendedores de outras populações, por exemplo, os gerentes (MCCLELLAND, 1971 apud OLIVEIRA; GUIMARÃES, 2008).

David Clarence McClelland é considerado o autor de maior destaque no meio acadêmico e nos estudos de empreendedorismo, com base na linha comportamental, ao desenvolver a Teoria das Necessidades Adquiridas, que destaca que as pessoas agem motivadas por suas necessidades de realização, afiliação e poder, que são adquiridas com seu desenvolvimento natural. Ele relata que todos têm essas necessidades, entretanto em níveis diferentes, mas uma delas sempre se destaca (FONSECA, 2010; SEBRAE, 2013). As necessidades que motivam as pessoas são descritas no Quadro 2. 
Quadro 2: Necessidades de motivação

\begin{tabular}{|l|l|}
\hline NECESSIDADE & DEFINIÇÃ̃ \\
\hline $\begin{array}{l}\text { Realização } \\
\text { (n-Achievement) }\end{array}$ & $\begin{array}{l}\text { É a necessidade em ter realização e ser motivado pela procura. } \\
\text { Testar seus limites e buscam realizar um bom trabalho. Pessoas } \\
\text { com este perfil tem uma grande necessidade de feedback e de se } \\
\text { sentir realizado. }\end{array}$ \\
\hline $\begin{array}{l}\text { Afiliação } \\
\text { (n-Affiliation) }\end{array}$ & $\begin{array}{l}\text { Estão relacionadas a indivíduos que buscam estabelecer, manter } \\
\text { e até restabelecer relações positivas com outras pessoas. }\end{array}$ \\
\hline $\begin{array}{l}\text { Poder } \\
\text { (n-Power) }\end{array}$ & $\begin{array}{l}\text { São necessidades das pessoas em exercer poder sobre outras, por } \\
\text { buscarem ser influentes e causarem impacto. }\end{array}$ \\
\hline
\end{tabular}

Fonte: Adaptado (MCCLELLAND, 1972 apud DIAS; SOUZA NETO; BOAS, 2010).

As pesquisas de McClelland (1971), permitiram que ele afirmasse categoricamente, que a necessidade de realização é o maior motivo para que as pessoas busquem empreender. Para o autor, pessoas com esse perfil tendem a se dedicar mais a tarefas desafiadoras e com riscos moderados, além disso, preferem depender de suas próprias habilidades para alcançarem seus resultados (OLIVEIRA; GUIMARÃES; 2008).

Visando a capacitação de empreendedores foi lançado em 1988 o Programa das Nações Unidas para o Desenvolvimento (PNUD), com base em estudos realizados por McClelland e Winter (1971) e McClelland (1972). Este projeto pôde identificar dez principais Características Comportamentais do Empreendedor (CCE), das quais o empreendedor deve ter, desenvolver ou apenas que aprimorar para ser bem-sucedido. Essas características são as mesmas utilizadas pelo SEBRAE no EMPRETEC (Seminário intensivo destinado a aumentar o potencial do empreendedor para melhor gerir o seu empreendimento ou para iniciar um negócio bemsucedido), como instrumento de auto avaliação.

O motivo de definir as CCE não é somente identificar as características no comportamento das pessoas, também consiste em permitir a possibilidade de aprendizagem, desenvolvimento e aperfeiçoamento dessas características. Pensando nisso, elas foram agrupadas em três grupos distintos e correlacionados, favorecendo o entendimento dos possíveis resultados a partir da prática de comportamentos empreendedores (SEBRAE, 2013). São eles: Planejamento, Realização e Poder, os quais são descritos abaixo no Quadro 3. 
Quadro 3: Definição das Características do Comportamento Empreendedor

\section{Conjunto de Realização}

\section{CCE: Busca de oportunidades e iniciativa}

Age antes de ser solicitado, ou antes de ser forçado pelas circunstâncias; busca expandir o negócio a novas áreas, produtos ou serviços; procura aproveitar oportunidades fora do comum para começar um negócio, obter financiamentos, equipamentos, terrenos, locais de trabalho ou assistência.

\section{CCE: Correr riscos calculados}

Consiste em avaliar alternativas e calcular riscos deliberadamente; agir para reduzir os riscos ou controlar os resultados; também colocar-se em situações que implicam desafios ou riscos moderados.

\section{CCE: Persistência}

Procura agir diante de um obstáculo significativo; busca agir repetidamente ou mudar de estratégia, a fim de enfrentar um desafio ou ultrapassar um obstáculo; faz um sacrifício pessoal ou desenvolve um esforço extraordinário para completar uma tarefa.

\section{CCE: Exigência de qualidade e eficiência}

Encontra meios de fazer as coisas, melhor, mais rápido ou mais barato; age de maneira que satisfaz ou excede os padrões de excelência; desenvolve ou utiliza procedimentos para assegurar o termino do trabalho a tempo ou de forma que atenda a padrões de qualidade previamente combinados.

\section{CCE: Comprometimento}

Assume a responsabilidade no desempenho necessário ao atingimento de metas e objetivos; colabora com os empregados ou se coloca no lugar deles, se necessário, para finalizar um trabalho; busca manter os clientes satisfeitos e coloca em primeiro lugar a boa vontade a longo prazo, acima do lucro a curto prazo.

\section{CCE: Busca de informações}

\section{Conjunto de Planejamento}

Dedica-se a obter informações de clientes, fornecedores e concorrentes; também investiga como fabricar um produto ou fornecer um serviço; consulta especialista para obter Assessoria técnica ou comercial.

\section{CCE: Estabelecimento de metas}

Estabelece metas e objetivos que o desafiam além de ter um significado pessoal; define metas de longo prazo, claras e específicas; estabelece objetivos mensuráveis e de curto prazo.

\section{CCE: Planejamento e monitoramento sistemáticos}

Faz o planejamento de grandes tarefas em subtarefas com prazos definidos; revisa seus planos constantemente, levando em conta os resultados obtidos e mudanças circunstanciais; mantém registros financeiros e utiliza-os para tomar decisões.

\section{CCE: Persuasão e redes de contato}

\section{Conjunto de Poder}

Para influenciar ou persuadir os outros utiliza estratégias deliberadas; utiliza pessoas-chave como agentes na busca em atingir seus próprios objetivos; age para desenvolver e manter relações comerciais.

\section{CCE: Independência e autoconfiança}

Busca autonomia quanto a normas e controles de outros; mantém seu ponto de vista, mesmo diante da oposição ou de resultados inicialmente desanimadores; mostra confiança na sua própria capacidade de completar uma tarefa difícil ou de enfrentar um desafio.

Fonte: Adaptado de McClelland (1972) apud Dias, Souza Neto e Boas (2010). 


\section{Empreendedorismo Feminino}

Ultimamente a participação ativa na geração de novos negócios, pela mulher, tem aumentado consideravelmente no mundo todo. Meira, Durante e Oliveira (2008) relatam que as mulheres têm buscado no empreendedorismo uma forma de complementar as suas rendas familiares, e, cada vez mais tem assumido o sustento da família, ampliando assim sua participação na economia.

Um mundo onde a voz feminina vem ganhando força, como vemos nas manifestações de igualdade no trabalho, equiparação salarial, um reconhecimento maior do esforço feminino, a mulher vem se adaptando e se preparando cada vez mais para o que está sendo exigido. Conciliar a jornadas de trabalho juntamente com familiar virou uma rotina normal em muitas casas.

Para avaliar a situação atual das mulheres empreendedoras, pode-se analisar a pesquisa do GEM (2015), que apresenta dados atuais, em relação ao empreendedorismo. A participação das mulheres no mercado brasileiro pode ser comprovada a partir dos dados desta pesquisa, os quais, mostram que a igualdade de gênero em relação ao empreendedorismo, é uma das características marcantes no país. Entretanto, de acordo com Cassol (2006), apesar dos dados atuais serem positivos para as mulheres, ainda há evidências de desvantagens em função do gênero neste segmento do empreendedorismo, pois as mesmas enfrentam estereótipos de inferioridade quanto ao sexo masculino, principalmente no acesso a recursos financeiros.

Neste sentido, pode-se afirmar que programas de incentivo ao empreendedorismo feminino são necessários e estratégicos quando se pensa em criar condições favoráveis ao incremento do empreendedorismo feminino no país (GEM, 2015). É necessário manter este tipo de revolução que busca garantir direitos iguais para as mulheres, no trabalho e na família, e assim, continuar modificando as instituições, as estruturas sociais e as culturas que formam a base da sociedade (MEIRA; DURANTE; OLIVEIRA, 2008).

Com base ainda na pesquisa do GEM (2015) em empreendimentos em estágio inicial, os homens representam $21,7 \%$ dos empreendedores ativos, enquanto as mulheres $20,3 \%$. Em relação ao empreendedorismo em fases já estabelecidas, as taxas, de acordo com o gênero, mostram que 21,3\% dos empreendedores são homens e 16,6\% são mulheres. Há predominância de homens nos empreendimentos estabelecidos dos países, independentemente do nível da economia do país, a exemplo de Alemanha, EUA e México. 


\section{O personal trainer}

A busca por profissionais para auxiliar nas atividades físicas tem se tornado cada vez mais frequentes. Um dos fatores que favorecem essa procura é o aumento da utilização dos recursos tecnológicos, que na maioria das vezes acabam se tornando um mal necessário, pois ao mesmo tempo em que facilitam o dia a dia das pessoas, podem transformar boa parte delas em sedentárias, podendo ainda, ocasionar problemas de saúde futuros (SALCEDO, 2010).

Tendo em vista este propósito, nota-se que se tornou comum contratar o acompanhamento de um Personal Trainer. Devido à necessidade de horários flexíveis, treinos personalizados, exclusividade e maior acesso as informações. O mercado de trabalho fez com que surgisse de forma rápida este tipo de profissional, para diferentes públicos e em diferentes áreas (BLOSSE, 2009).

O personal trainer é como um especialista que busca o alcance de uma vida mais saudável dos seus alunos ajudando e influenciando na atividade corporal com preparação e equilíbrio dos exercícios (SALCEDO, 2010). Sanches (2006 apud Bossle, 2009), é um profissional formado em educação física que oferece um conjunto de atividades personalizadas para cada tipo de aluno. Dentre as várias definições, de maneira mais genérica Domingues Filho (2006), considera como um profissional de educação física que oferece aulas particulares.

As exigências necessárias para ser personal trainer são a graduação em educação física, certificada pelo Ministério da Educação (MEC) e o registro no Conselho Federal de Educação Física (CONFEF) e no representante regional, o CREF, que atua como órgão fiscalizador desta categoria profissional (SANCHES, 2006 apud BOSSLE 2009).

A jornada de trabalho varia de acordo com os horários e datas estabelecidas com cada aluno, ou seja, a qualquer hora ou dia podendo incluir finais de semana ou até mesmo feriados. Normalmente não possui vínculo empregatício e na maioria das vezes o contrato é feito de maneira informal através da forma verbal entre o aluno e treinador, o que causa certa instabilidade profissional (BOSSLE, 2009).

Como não possui lugar fixo para atuar, faz-se necessário o seu deslocamento para uma academia, residência, parque ou condomínio para realização do treino, sendo fundamental a adaptação do ambiente com uma série de equipamentos básicos ou até mesmo o improviso usando a criatividade com materiais comuns como: cadeira, cabo de vassoura, sofá etc. (SALCEDO, 2010). 


\section{Procedimentos Metodológicos}

A pesquisa é de natureza qualitativa, do tipo descritiva, a qual, segundo Bruni (2011), tem como função principal resumir dados e informações investigadas, expondo-os da maneira mais prática e simples possível. Ela tem como objetivo identificar e explicar os aspectos de um determinado público ou acontecimento, por meio da utilização de procedimentos técnicos de levantamento para conhecer certa conduta de um grupo significativo de pessoas, por meio de um questionamento direto.

Para estabelecimento da amostra buscou-se informações na Prefeitura de Petrolina-PE, onde foi informado que existem trinta academias regulares no município, e após visitas ocorridas, foram encontradas quatorze profissionais graduadas e com o certificado de educação física (CREF).

O tipo de análise realizada diante dos dados levantados foi o censo, que de acordo com Lopes (1999) consiste no estudo de toda a população, e, ele ainda ressalta que é viável fazê-lo quando a população em estudo for pequena. No caso da cidade de Petrolina-PE, a quantidade de profissionais que atuam como personal trainer é pequena, o que justifica o uso do censo, para dar mais significância à pesquisa.

Em análise estatística, a variável é uma representação de cada característica de uma unidade de observação, por um número. Quando uma característica ou variável não é numérica, chama-se de variável qualitativa (LOPES, 1999). Segundo Bruni (2011) uma variável qualitativa não pode ser comparada ou operada matematicamente. O estudo em questão utilizou um questionário que colhia informações a partir de variáveis não-numéricas.

A análise qualitativa de um problema justifica-se, sobretudo, por permitir o entendimento da natureza de um fenômeno social. É uma modalidade muito empregada por pesquisadores, que visa transformar em elementos quantificáveis, os dados qualitativos abordados. Para isso, emprega critérios, categorias ou escalas de atitude como parâmetros, ou ainda, identifica o grau ou a intensidade com que um conceito, uma atitude ou uma opinião é manifestada (RICHARDSON, 1999).

Para coleta de dados foi utilizado um questionário de autoavaliação do indivíduo, contendo perguntas objetivas com relação ao cotidiano desse profissional, além de questões afirmativas que faziam parte de um modelo proposto, para que pudesse analisar a relação de causa e de efeito do problema exposto. Este questionário foi composto de 70 questões, onde as 
oito primeiras eram as perguntas de caráter pessoal. As demais questões, se tratavam de afirmações que a profissional deveria responder, fazendo uma autoavaliação, com base em uma escala Likert, de 5 pontos, onde os números (1, 2, 3, 4 e 5) representam (nunca, raras vezes, algumas vezes, usualmente e sempre), respectivamente.

O questionário com as 63 questões utilizado na pesquisa, foi adaptado a partir do teste desenvolvido pela empresa de McClelland (McBer \& Company), que teve como base, o conjunto de comportamentos e características individuais, que foram identificados por McClelland (1987), e, posteriormente este conjunto foi revisado e complementado por Cooley (1990). O motivo da confecção de um novo teste foi a experiência dos desenvolvedores e a insatisfação dos participantes com o resultado obtidos no questionário da empresa de McClelland (CASTRO, 2011).

Como o trabalho foi direcionado à atuação da mulher como personal trainer, as profissionais que atuam somente como professoras das academias, ou seja, que são somente instrutoras, não entraram na seleção de pesquisa, pelo fato de estarem vinculadas apenas na empresa.

\section{Resultados e Discussões}

De acordo com os resultados obtidos, pôde-se observar que apenas algumas das profissionais aperfeiçoaram sua formação acadêmica, pois, das 14 profissionais entrevistadas, apenas 3 foram além da graduação, conforme apresentado na Tabela 1. Tal resultado pode estar ligado a rotina múltipla das profissionais, tais como cuidar dos filhos, família, rotina profissional, ou acomodação.

Tabela 1: Formação Acadêmica das entrevistadas

\begin{tabular}{lr}
\hline \multicolumn{2}{c}{ GRAU DE } \\
\multicolumn{2}{c}{ ESCOLARIDADE } \\
\hline Especialização & $14,28 \%$ \\
Graduação & $78,57 \%$ \\
Pós-graduação & $7,14 \%$ \\
\hline Fonte: Pesquisa do autor
\end{tabular}


A média da idade das participantes foi de 32 anos de idade como pode ser visto na Tabela 2, e ainda se percebe uma diferença notória entre a idade máxima e a mínima das profissionais.

Tabela 2: Idade das entrevistadas

\begin{tabular}{lr}
\hline \multicolumn{2}{c}{ IDADE } \\
\hline Média & 32 \\
Desvio padrão & 5 \\
Máximo & 45 \\
Mínimo & 25 \\
\hline
\end{tabular}

Fonte: Pesquisa do autor

Na Tabela 3 pode-se observar a média representativa da quantidade de locais onde as profissionais atuam. Vale ressaltar que talvez pela facilidade para ministrar suas aulas, tais profissionais preferem realizá-las nas próprias academias. Porém, com relação à quantidade de alunos, pode-se observar uma variação.

Tabela 3: Quantidade de alunos e os locais de atuação

\begin{tabular}{lrlr}
\hline QUANTIDADE DE & \multicolumn{2}{c}{ LOCAIS DE ATUAÇÃO } \\
ALUNOS & 5 & Média & 1,4 \\
\hline Média & 2 & Mínimo & 1 \\
Mínimo & 10 & Máximo & 3 \\
Máximo & 70 & & \\
Contagem & \multicolumn{2}{c}{} \\
\hline
\end{tabular}

Fonte: Pesquisa do autor

Outro fato interessante que pode ser observado na Tabela 3, é a quantidade de alunos que usufruem deste tipo de serviço em relação a quantidade de profissionais, que pode ser considerada razoável visto que a quantidade de profissionais é pequena em relação ao tamanho da cidade. O serviço envolve o atendimento privativo destes alunos pelas instrutoras, em horários estabelecidos, acompanhando e instruindo a prática dos exercícios físicos.

A maioria das profissionais entrevistadas recebem de 1200 a 3000 reais mensalmente, como pode ser visto na Tabela 4. A renda das profissionais varia muito de acordo com a quantidade de alunos que cada uma delas está disposta a acompanhar, o público alvo atendido e o tipo de serviço personalizado. 
Tabela 4: Renda mensal média das profissionais.

\begin{tabular}{lr} 
RENDA MENSAL & QUANTIDADE \\
R\$ 1200 a 3000 & $64,28 \%$ \\
R\$ 3001 a 9000 & $35,71 \%$ \\
\hline
\end{tabular}

Fonte: Pesquisa do autor

As outras quatro características do conjunto de realização, apresentado na Figura 1, obtiveram a pontuação mediana de 4 , assim como a maioria das CCE observadas no presente estudo. Oito das onze características apresentaram este resultado. Por sua vez, Sharma e Laroiya (2008) realizaram um estudo, que se baseou na metodologia de McClelland e foi apresentado na World Conference Proceedings do Conselho Internacional para Pequenas Empresas (ICSB), no qual os autores analisaram a diferença das CCE entre homens e mulheres empreendedores na Índia, através de uma amostra composta por 50 indivíduos de cada sexo. Neste estudo, constatou-se a aversão das mulheres em correr riscos, assim como foi visto neste trabalho, o que pode ser observado na Figura 1, na CCE correr riscos calculados que foi 3,5.

Figura 1: Conjunto de realização

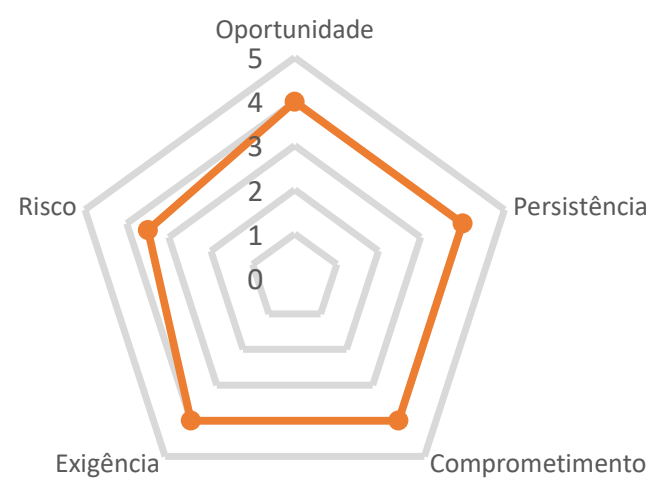

Fonte: Sharma e Laroiya (2008)

Nos achados de Dias, Martens e Boas (2012), com base na metodologia de McClelland, foi observado a menor pontuação para a CCE correr riscos calculados. As autoras também citam que este mesmo resultado, quanto a posição da característica, foi observado em outros trabalhos semelhantes, como Silva et al. (2008), Schmidt e Dreher (2008) e Lengler e Silva (2008). 
O segundo conjunto, de planejamento, é apresentado na Figura 2, o qual é composto por três características, onde duas delas tiveram destaque nesta pesquisa. A CCE "estabelecimento de metas", que neste trabalho foi uma das duas com menor pontuação observada, nas profissionais entrevistadas, possui um resultado que difere do que foi visto no trabalho de Dias, Martens e Boas (2012), no qual esta característica teve a maior pontuação entre todas as características estudadas. Se tratando da CCE "busca de informação”, que nesta pesquisa obteve a maior pontuação, as autoras obtiveram um resultado parecido, pois esta característica, no trabalho delas, teve a segunda maior pontuação.

Figura 2: Conjunto de planejamento

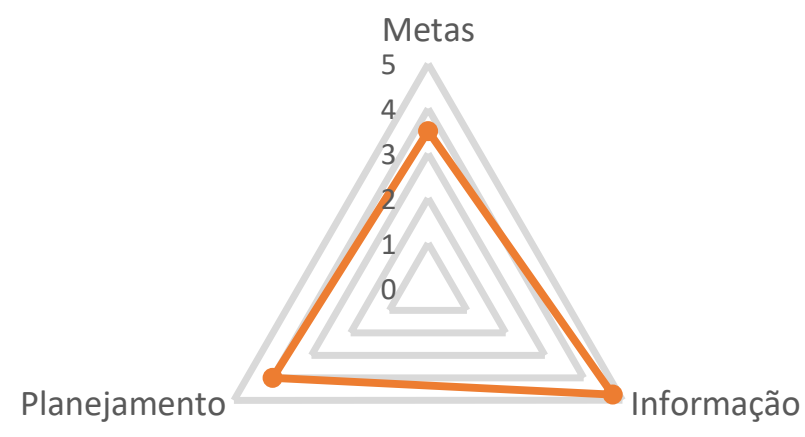

Fonte: Sharma e Laroiya (2008)

O que se pode observar a partir da Figura 2, é que as entrevistadas têm buscado informação, ou seja, tem se mantido em aprendizado, um fator relevante para se desenvolver profissionalmente. Ao menos, isso é o que se espera, por elas terem obtido a pontuação de 4,75 na CCE busca de informação. Entretanto, este resultado é um pouco contraditório se for levado em consideração que apenas três das quatorze participantes da pesquisa fizeram alguma pósgraduação. No quesito estabelecer metas, as profissionais abordadas estão um pouco desiguais, em relação às outras características. Na CCE planejamento e monitoramento sistemático, tiveram uma melhor avaliação que na CCE estabelecimento de metas, o que leva a crer que elas tenham um bom desempenho planejando os seus objetivos, entretanto, a definição desses objetivos parece ser um obstáculo maior.

No terceiro conjunto, o conjunto de poder, apresentado na Figura 3, todas as características apresentaram a mediana 4, mostrando um bom desempenho das participantes. Entretanto, como a escala que foi utilizada no estudo vai até o valor 5, pode-se concluir que são 
características que ainda podem ser desenvolvidas pelas participantes. Tal resultado pode ter sido alcançado pela vontade das profissionais em conseguir uma posição e reconhecimento profissional melhor, assim como sua independência, uma vez que a maioria delas ainda trabalha, não somente com alunos particulares, mas também nas academias como instrutoras.

Figura 3: Conjunto de poder

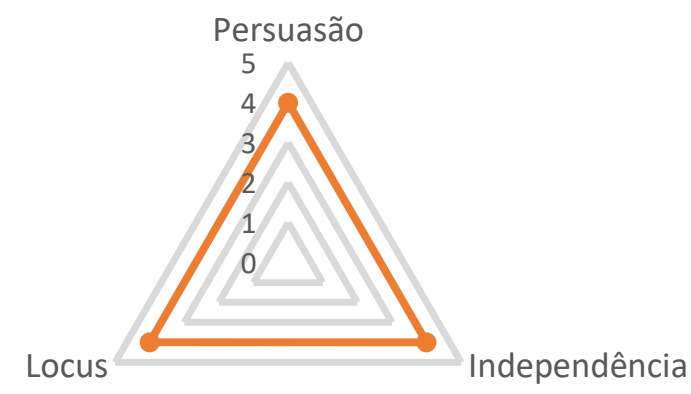

Fonte: Sharma e Laroiya (2008)

O conjunto do poder está ligado a indivíduos que confiam em seu potencial para resolver as atividades que lhes foram confiadas e/ou possuem habilidades para persuadir as pessoas que precisam, de forma estratégica, na busca por alcançar seus objetivos (SEBRAE, 2013). Além disso, esse conjunto abrange a característica de lócus de controle interno que está ligada a empreendedores que acreditam que podem controlar seus destinos planejando-os e que gostam de autonomia (HISRICH; PETERS, 1998 apud SCHERMERHORN, 2007).

Portanto, as características desse conjunto são muito importantes para o empreendedor obter sucesso. Para as personais trainers não é diferente, essas características também são necessárias para que elas possam manter uma boa relação com seus clientes e construir um vínculo duradouro, sendo benéfico para ambos. Além disso, este conjunto remete a um comportamento que é confiar no próprio potencial, o qual é importante para qualquer empreendedor que busca realizar suas tarefas e superar seus limites de forma eficaz. Acreditar que pode traçar o próprio destino, com foco e planejamento, também é uma característica valiosa.

Algumas características tiveram uma menor pontuação neste trabalho em relação aos resultados de pesquisas anteriores, são elas: correr riscos calculados, 3,5 e estabelecimento de 
metas, 3,5. A característica que teve o maior destaque na pesquisa foi busca por informação (5). Todas as outras características apresentaram o valor de mediana 4, mostrando um bom desempenho das participantes, mas que também podem ser aperfeiçoadas.

\section{Considerações finais}

O estudo do empreendedorismo é muito relevante, e, ao mesmo tempo, um tema muito complexo. Portanto, entender os motivos que levam as pessoas a ter a iniciativa de criar um negócio próprio, assim como identificar o perfil desses indivíduos antes e durante a implantação e desenvolvimento do empreendimento, são fatores relevantes para o entendimento desta arte.

O objetivo deste trabalho foi delinear o perfil empreendedor, das mulheres que atuam como personal trainer, na cidade de Petrolina-PE, para identificar em quais níveis, as características do comportamento empreendedor, estão presentes no perfil destas profissionais. Para isso, foi feito um questionário com as 14 mulheres que tem exercido a profissão de personal trainer atualmente em Petrolina-PE, visando identificar o perfil e as características do comportamento empreendedor das mesmas, assim como propiciar a reflexão sobre a prática de comportamentos empreendedores no dia a dia.

Dentre as características empreendedoras observadas, uma delas teve destaque na pesquisa, a CCE busca de informação. O que nos mostra que as entrevistadas têm ido em busca de conhecimento para aperfeiçoar seu desempenho profissional, característica importante para quem busca sucesso em empreender. Em contrapartida, as CCE correr riscos calculados e estabelecimento de metas, que apresentaram a mesma mediana nos resultados, foram as que tiveram a pontuação mais baixa mostrando que as profissionais ainda que estando empenhadas na sua melhoria profissional preferem ter mais estabilidade e cautela quanto a correr riscos e também se nota uma necessidade de melhoria no estabelecimento de metas. As outras oito características (busca de oportunidades e iniciativa, persistência, exigência de qualidade e eficiência, comprometimento, planejamento e monitoramento sistemáticos, persuasão e redes de contato, independência e autoconfiança) apresentaram a mesma mediana como resultado na pesquisa, sendo 4 em uma escala até 5.

Independente da pontuação das características do comportamento empreendedor analisadas nesta pesquisa, o que vale ressaltar é que todas elas podem ser desenvolvidas e 
aperfeiçoadas, pois nenhuma delas alcançou a pontuação máxima. De acordo com McClelland (1978 apud DIAS, SOUZA NETO E BOAS 2010), através de programas específicos, essas competências podem ser desenvolvidas, proporcionando sucesso aos indivíduos que buscam desenvolver este perfil empreendedor, assim como tem aqueles que desenvolveram essas características naturalmente.

Este trabalho contribui para o entendimento da história e dos conceitos do empreendedorismo de forma geral e do empreendedorismo feminino. Além disso, colabora com a compreensão dos motivos que levam as pessoas a empreenderem, assim como das características de comportamento que são mais observadas nos empreendedores de sucesso. Também é apresentada uma contextualização do profissional personal trainer. Assim, esse estudo também pode ajudar as profissionais avaliadas, caso elas queiram, a aperfeiçoar seu perfil empreendedor, podendo desenvolver uma didática de aprendizado com foco nas características mais necessárias, de acordo com os resultados.

Uma limitação deste estudo, foi que o número de profissionais que se enquadravam no perfil analisado, era pequeno, restringindo um pouco os resultados, assim como, a dificuldade em marcar uma hora para fazer as entrevistas também foi um obstáculo, visto que o horário destas profissionais é perceptivelmente muito concorrido e quase sempre elas estão com seus alunos ou dentro das academias atuando como instrutoras.

Os dados apresentados neste estudo servem de base para outros estudos mais abrangentes e para estudos específicos da área, que confirmem a importância dessas características, contribuam para o surgimento de novas iniciativas e que possam despertar o potencial de mais empreendedores. O tema empreendedorismo é muito complexo e por isso ainda carece de informações, assim como o empreendedorismo feminino, que tem se intensificado, entretanto, ainda necessita de incentivos e aporte teórico e prático para um melhor desenvolvimento.

\section{Referências}

ALDRICH, H. E. The emergence of entrepreneurship as an academic field: A personal essay on institutional entrepreneurship. Research Policy, v. 41, n. 7, p. 1240-1248, set. 2012. Disponível em: < http://www.sciencedirect.com/science/article/pii/S0048733312000741>. Acesso em: 15 de abr de 2017. 
ALPERSTEDT, G. D.; FERREIRA, J. B.; SERAFIM, M. C. Empreendedorismo feminino: dificuldades relatadas em histórias de vida. Revista de Ciências da Administração, p. 221-234, 2014. Disponível em: < https://periodicos.ufsc.br/index.php/adm/article/view/21758077.2014v16n40p221>. Acesso em: 12 de maio de 2017.

BAGGIO, A. F.; BAGGIO, D. K. Empreendedorismo: Conceitos e definições. Revista de Empreendedorismo, Inovação e Tecnologia. v.1, n.1, p. 25-38, 2015. Disponível em: < https://seer.imed.edu.br/index.php/revistasi/article/view/612>. Acesso em: 20 de maio de 2017.

BOSSLE, C. B. "Personal Trainer \& Cia": noções de marketing na literatura sobre treinamento personalizado. 2009. 92 f. Dissertação (Mestrado) - Escola de Educação Física, UFRGS, Porto Alegre, 2009. Disponível em: <http://www.lume.ufrgs.br/handle/10183/18271>. Acesso em 20 de abril de 2017.

BOSSLE, C. B.; FRAGA, A. B. O personal trainer na perspectiva do marketing. Revista Brasileira de Ciências do Esporte, v. 33, n. 1, 2011. Disponível em: <http://www.oldarchive.rbceonline.org.br/index.php/RBCE/article/view/636>. Acesso em: 20 de abr de 2017.

BRUNI, A. L. Estatística aplicada à gestão empresarial. Atlas. $3^{\circ}$ ed. p. 398, 2011.

CASTRO, A. A. Um modelo de avaliação dos antecedentes do empreendedorismo corporativo. Percurso Acadêmico, v. 1, n. 2, p. 359-362, 2013. Disponível em: < http://periodicos.pucminas.br/index.php/percursoacademico/article/view/5417>. Acesso em: 10 de abr de 2017.

CASSOL, N. K. (2006). A produção científica na área de empreendedorismo feminino: análise dos estudos indexados na base de dados do Institute for Scientific Information (ISI). 2006. Dissertação (Mestrado em Administração) - Universidade Regional de Blumenau, Blumenau. Disponível em: < http://www.bc.furb.br/docs/DS/2006/322073_1_1.pdf>. Acesso em 28 de abr de 2017.

DIAS, T.R.F.V.; MARTENS, C.D.P.; BOAS, A.A.V.B. Estudo das características comportamentais empreendedoras dos estudantes membros de duas empresas juniores. Simpósio de administração da produção, logística e operações internacionais, v. 15, 2012. Disponível em: http://www.simpoi.fgvsp.br/arquivo/2012/artigos/E2012_T00241_PCN02186.pdf>. Acesso em: 10 de maio de 2017.

DIAS, T. R. F. V.; SOUZA NETO, S.P.; BOAS, A. A. V. Características Comportamentais Empreendedoras Relevantes: Estudo de Caso dos Ganhadores do Prêmio TOP Empresarial 2007. 2010. Disponível em: < http://www.anegepe.org.br/edicoesanteriores/recife/EMP103.pdf>. Acesso em: 10 de maio de 2017.

DI BARTOLOMEO, R.; STAHL, F. H.; EliAS, D. C.. A Importância do Ensino de Empreendedorismo para os Gestores de Recursos Humanos. REPAE-Revista de Ensino e 
Pesquisa em Administração e Engenharia, v. 1, n. 2, p. 148-168, 2016. Disponível em: < http://www.repae.org/index.php/REPAE/article/view/22>. Acesso em: 12 de maio de 2017.

DOMINGUES FILHO, L. A. Manual do Personal Trainer Brasileiro. São Paulo: Ícone, 2006. Disponível em:

http://www.iconeeditora.com.br/pdf/405192212Manual\%20do\%20Personal\%20Trainer_2015 _1a19.pdf>. Acesso em 15 de maio de 2017.

DORNELAS, J. Empreendedorismo: transformando ideias em negócios. 6 ed. São Paulo: Empreende/Atlas, 2016.

FONSECA, G. C. Empreendedorismo e Intraempreendedorismo: Estudo de caso sobre o perfil McClelland em uma empresa varejista farmacêutica. Belo Horizonte, 2010. Dissertação (Mestrado em Administração) - Faculdades Novos Horizontes/MG. Disponível em: < http://unihorizontes.br/novosite/banco_dissertacoes/141220111509445819.pdf>. Acesso em: 29 de abr de 2017.

GARTNER, W. B. "Who is an Entrepreneur?" Is the Wrong Question. American Journal of Small Business, v. 12, n. 4, p. 11-32, 1988. In: CASTRO, A. A. UM MODELO DE AVALIAÇÃO DOS ANTECEDENTES DO EMPREENDEDORISMO CORPORATIVO. Percurso Acadêmico, v. 1, n. 2, p. 359-362, 2013.

GEM - Global Entrepreneurship Monitor. Empreendedorismo no Brasil - 2009: relatório nacional. Curitiba: IBQP, 2010.

2015 Curitiba IBPQ. p. 178. 2014 GEM 2015. 2016.

HISRICH, R. D.; PETERS, M. P. Entrepreneurship. 4th ed. New York: Irwin/McGraw-Hill, 1998, pp. 70-74. In: SCHERMERHORN, Jr. J. R. Administração. $8^{\mathrm{a}}$ ed. Rio de Janeiro: LTC, 2007.

HISRICH, R. D.; PETERS, M. P.; SHEPHERD, D. A. Empreendedorismo. Tradução: Tereza Cristina Felix de Souza. 2009. AMGH Editora, 2014.

KANAN, L. A. Poder e liderança de mulheres nas organizações de trabalho. Revista $O \& S$, Salvador, v. 17, n. 53, art. 1, p. 243-257, abr-jun, 2010. Disponível em: < https://portalseer.ufba.br/index.php/revistaoes/article/view/11104> Acesso em: 12 de maio de 2017.

LANDSTROM, H.; BENNER, M. Entrepreneurship research: a history of scholarly migration. In: LANDSTROM, H.; LOHRKE, F. (org). Historical foundations of entrepreneurship research. Great Britain: Edward Elgar Publishing. p. 15-45, 2010. Disponível em: < https://books.google.com.br/books?hl=pt-

BR\&lr=\&id=BB7Zes_BZtgC\&oi=fnd\&pg=PA15\&dq=Historical+foundations+of+entreprene urship+research.+Great+Britain:+Edward+Elgar+Publishing.+p.+15-

45,+2010.\&ots=7oGQdASdFj\&sig=Vr4HHOXjDCJ5TjuXAjVIS-

EwHfw\#v=onepage\&q\&f=false>. Acesso em 17 de abr de 2017. 
LENGLER, L.; SILVA, T. N. Empreendedorismo: uma perspectiva do perfil dos membros de uma associação apícola. ENCONTRO DE ESTUDOS SOBRE EMPREENDEDORISMO E

GESTÃO DE PEQUENAS EMPRESAS. Anais... São Paulo. 2008.

LOPES, P. A. Probabilidades \& estatística. Rio de Janeiro: Reichmann \& Affonso, 1999.

MCCLELLAND, D. C. The achievement motive in economic growth. In: KILBY, Peter. (Ed.) Entrepreneurship and economic development. New York: The Free Press, 1971. p. 109-122. In: OLIVEIRA, D. C.; GUIMARÃES, L. O. Perfil empreendedor e ações de apoio ao empreendedorismo: o NAE/SEBRAE em questão. Economia \& Gestão, v. 6, n. 13, 2008.

A sociedade competitiva: realização \& progresso social. Rio de Janeiro: Expressão e Cultura, 1972. In: DIAS, T. R. F. V.; SOUZA NETO, S.P.; BOAS, A. A. V. Características Comportamentais Empreendedoras Relevantes: Estudo de Caso dos Ganhadores do Prêmio TOP Empresarial 2007. 2010.

MEIRA, C.; DURANTE, R. L.; OLIVEIRA, L. S. Empreendedorismo Feminino: casos de sucesso de empresárias do Sudoeste do Paraná. In: Anais do Congresso Internacional de Administração, 2008, Ponta Grossa. Anais do ADM 2008, Ponta Grossa.

METZ, Eduardo Silva. Gestão feminina: a presença das mulheres na liderança de empresas. Ágora: revista de divulgação científica, v. 19, n. 2, p. 169-178, 2015. Disponível em: < http://www.periodicos.unc.br/index.php/agora/article/view/667>. Acesso em: 22 de maio de 2017.

MURPHY, P.; LIAO, J.; WELSCH, H. P. A conceptual history of entrepreneurial thought. Journal of Management History, v. 12, n. 1, p.12-35, 2006. Disponível em: <http://www.emeraldinsight.com/doi/full/10.1108/13552520610638256>. Acesso em: 22 de abr de 2017.

NOGUERA, M.; ALVAREZ, C.; URBANO, D. Sociocultural factors and female entrepreneurship. Spriger Science+Business Media New York, USA, 2013. In: ALPERSTEDT, G. D.; FERREIRA, J. B.; SERAFIM, M. C. Empreendedorismo feminino: dificuldades relatadas em histórias de vida. Revista de Ciências da Administração, p. 221-234, 2014.

OLIVEIRA, D. C.; GUIMARÃES, L. O. Perfil empreendedor e ações de apoio ao empreendedorismo: o NAE/SEBRAE em questão. Economia \& Gestão, v. 6, n. 13, 2008. Disponível em:

http://ws3.pucminas.br/imagedb/documento/DOC_DSC_NOME_ARQUI20070528113356.p df>. Acesso em 15 de maio de 2017.

OLIVEIRA, R. C. Personal Training. São Paulo: Etheneu, 1999. In: SALCEDO, J. F. Os motivos à prática regular do treinamento personalizado: um estudo com alunos de personal trainer. Trabalho de conclusão de curso apresentado à Universidade Federal do Rio Grande do Sul. Porto Alegre, 2010. Disponível em: < http://www.lume.ufrgs.br/handle/10183/27743>. Acesso em 28 de abril de 2017. 
RICHARDSON, R. J. Pesquisa Social: métodos e técnicas. 3 ed. revista e ampliada. São Paulo: Editora Atlas S.A., 1999. Disponível em: < https://www.scribd.com/doc/226198537/01Richardson-Pesquisa-Social-MCtodos-e-TCcnicas-pdf-PdfCompressor-643562>. Acesso em 05 de maio de 2017

SALCEDO, J. F. Os motivos à prática regular do treinamento personalizado: um estudo com alunos de personal trainer. Trabalho de conclusão de curso apresentado à Universidade Federal do Rio Grande do Sul. Porto Alegre, 2010. Disponível em: < http://www.lume.ufrgs.br/handle/10183/27743>. Acesso em 28 de abril de 2017.

SANCHES, E. W. Responsabilidade civil das academias de ginásticas e do personal trainer. São Paulo: Editora Juarez de Oliveira, 2006. In: BOSSLE, C. B. "Personal Trainer \& Cia": noções de marketing na literatura sobre treinamento personalizado. 2009. 92 f. Dissertação (Mestrado) - Escola de Educação Física, UFRGS, Porto Alegre, 2009.

SCHMIDT, C. M.; DREHER, M. T. Cultura Empreendedora: Empreendedorismo Coletivo e Perfil Empreendedor. Revista de Gestão. Universidade de São Paulo (USP), v. 15, n. 1, p. 1-14, 2008.

SCHUMPETER, J. A. The Theory of Economic Development. Cambridge, Mass.; Harvard University Press. $1949 . \quad$ Disponível em: https://books.google.com.br/books/about/The_Theory_of_Economic_Development.html?id=OZwWcOGeOwC\&redir_esc=y>. Acesso em: 14 de abr de 2017.

SCHUMPETER, J. A Teoria do desenvolvimento econômico: uma investigação sobre lucros, capital, crédito, juro e o ciclo econômico. São Paulo: Abril Cultural, 1982. Capitalismo, socialismo e democracia. Rio de Janeiro: Zahar Editores, 1984. Disponível em: < http://www.ufjf.br/oliveira_junior/files/2009/06/s_Schumpeter_-

_Teoria_do_Desenvolvimento_Econ\%C3\%B4mico_-

_Uma_Investiga\%C3\%A7\%C3\%A3o_sobre_Lucros_Capital_Cr\%C3\%A9dito_Juro_e_Ciclo _Econ\%C3\%B4mico.pdf>. Acesso em 16 de abr de 2017.

SEBRAE. Disciplina de Empreendedorismo. Modulo 1: O Empreendedor. Brasília/DF, 2013. Disponível

em: http://www.bibliotecas.sebrae.com.br/chronus/ARQUIVOS_CHRONUS/bds/bds.nsf/bc0a1b2 9c05ef9eb60a43c1303b881e8/\$File/5696.pdf . Acesso em: 20 de maio de 2017.

Os desafios da mulher empreendedora. Endeavor Brasil, 2016. Disponível em: https://www.sebrae.com.br/sites/PortalSebrae/artigos/os-desafios-da-mulher-
empreendedora,e74ab85844cb5510VgnVCM1000004c00210aRCRD>. Acesso em: 22 de maio de 2017.

SHARMA, D. D.; LAROIYA, S. C. A Comparative Analysis of Characteristics and Challenges of Male and Female Entrpreneurs in India. World Conference Proceedings of Internacional Council for Small Business, 2008. Disponível em: < http://search.proquest.com/openview/2470f54968e87dc5b3aaa76f7cbfd06d/1?pqorigsite $=$ gscholar \&cbl=39996> . Acesso em: 14 de maio de 2017. 
SILVA, S. S. da; SILVA, A. M. M. da; BOAS, V. A. A.; DAN, E. Características comportamentais empreendedoras: um estudo comparativo entre empreendedores $\mathrm{e}$ intraempreendedores. Rio de Janeiro: Revista Cadernos de Administração, v.1, n. 2, p. 1-14, 2008 .

\section{Como citar este artigo (Formato ABNT):}

GUT, Bruna C.P.; SANTOS, Marligia S..; OLIVERA, Erika M. J. de. A Mulher Empreendedora e o delineamento do perfil Profissional da Personal Trainer. Id on Line Rev.Mult. Psic., 2018, vol.12, n.40, p.315-335. ISSN: 1981-1179.

Recebido: 24/01/2018

Aceito 28/03/2018 